\title{
An Evaluative Study of Memorization as a Strategy for Learning English
}

\author{
Khalid Sabie Khamees ${ }^{1}$ \\ ${ }^{1}$ Department of English, College of Arts, Al-Iraqiya University, Bagdad, Iraq \\ Correspondence: Khalid Sabie Khamees, Department of English, College of Arts, Al-Iraqiya University, Bagdad, \\ Iraq. E-mail: Sundakhalid@gmail.com
}

Received: June 29, 2016 Accepted: July 15, 2016 Online Published: July 28, 2016

doi:10.5539/ijel.v6n4p248 URL: http://dx.doi.org/10.5539/ijel.v6n4p248

\begin{abstract}
This exploratory study elicits learners' views regarding the utility of using memorization as a strategy for learning English. It exclusively investigates the extent of learners' use of the memorization strategy, the reasons that motivate them to memorize, the problems they encounter and the techniques they resort to to overcome these problems. 66 undergraduate participants answered a thirty-item questionnaire. The results revealed that most efficient as well as inefficient learners used the memorization strategy mainly for learning vocabulary, definitions, and literary texts. They were in favour of using this strategy because it helps them improve their achievements in English. It was found that understanding should be given priority over the memorization activity. Learners who adopt this strategy often forget what they memorized, could not differentiate between important and unimportant information, and were incompetent to make inferences. It can be concluded that memorization is a low-level cognitive strategy that can be used among other high- level cognitive strategies in the process of learning English.
\end{abstract}

Keywords: comprehension, drawbacks, internalization, learning strategy, memorization

\section{Introduction}

\subsection{Learning Strategies}

Recent research in applied linguistics and psycholinguistics increasingly points to learning strategies (e.g., summarizing, inferencing and memorization) as the key activities in acquiring language (McDonough, 1995; Cotterall \& Reinders, 2004). It has shown that language learning is an active process in which learners apply various strategies to understand and internalize the components of language. Chamot et al. (1987, p. 71) defines learning strategies as "techniques, approaches or deliberate actions that students take in order to facilitate the learning and recall of both linguistic and content area information". Cohen $(1998$, p. 4) states that learning strategies are "those processes which are consciously selected by the learners and which may result in action taken to enhance the learning of second or foreign language, through the storage, retention, recall, and application of information about the language." O'Malley et al. (1985) classify learning strategies into three categories:

a. Metacognitive such as selective attention, directed attention and self-evaluation).

b. Cognitive strategies such as repetition, remembering, elaboration, inferencing, and summarizing.

c. Social strategies such as asking for clarification and cooperation.

This study sets out to investigate one of the cognitive strategies, namely, memorization, sometimes called rehearsal. This strategy involves saying or writing something over and over until the learner is able to reproduce the material automatically. According to Richards \& Schmidt (2013, p. 359), "memorization usually refers to the conscious process of establishing information in memory." This means that this strategy is a conscious process, i.e., it includes some mental activities intentionally carried out by speaker or writer. The Memorization Strategy (henceforth MS) is thought to be used by learners to facilitate their ability to learn language (Ozcan \& Kesen, 2008, p. 70). Cook (1994, p. 133) believes that repetition and learning by heart are two valuable and interesting language learning activities. They can give the learner an opportunity of practising authentic and communicative use of language. 


\subsection{Relation between Memorization and Comprehension}

Despite the fact that comprehension and memorization are two separate activities, it is commonly believed that each one complements the other. Obviously, most memorized language materials necessitate their understanding prior to the process of memorizing. The process of comprehension is a very complex one. Readers as well as listeners do not depend on one channel to attain the intended meaning; rather, they recruit the linguistic as well as non-linguistic information to interpret what they hear or read. Researchers (e.g., O’Malley \& Chamot, 1990, p. 36) mention that in processing received information learners use two types of information: bottom-up and top-down. The bottom-up approach makes use of information already present in the data, i.e., a learner tries to understand the literal meaning of the message (Marton, 1988, p. 50; Nunan, 1989, p. 25). On the other hand, the top-down processing makes use of various non-linguistic information to construct meaning. Riley (1981, p. 141) states that learners who depend solely on their linguistic competence are unable to interpret utterances in context if they do not possess the necessary situational and pragmatic information.

The present researcher suggests that the first step for unintentional natural memorization begins by comprehending an utterance, then, forming an idea that specifies the exact function of the utterance (speech act). Then, this idea will be stored in either short or long- term memories, depending on the frequency of the event recurrence. The retrieval of ideas does not necessarily be verbatim; rather, we remember the meaning that hinges on a person's ability to remember the images, feelings and sounds (situation) that have contributed to the generation of these ideas. Admittedly, the continuous recurrence of an action (idea) might unconsciously enable the speaker/ writer to recover its linguistic form literally. This type of memorization is appreciated and backed up. It can be suggested that such kind of activity might evolve and become a mechanical process that requires very little time and effort to carry out. At this stage, the mechanical reproduction will overtake, leaving the content as well as the structure lagging behind. Many authors (e.g., Krashen \& Terrell, 1983, p. 91; Wang, 1986, p. 108) underestimate the role of morphology in the process of listening, i.e., the meaning is retained while the morphological structure is deleted. Thus, when someone recites a poem, dances, or sings a song, it is possible that she/he just reproduces what has been memorized without paying attention to the words being said or the meaning contained, does not decide what the next step in an activity should be or evaluate what is being said or written. Here, her/his action resembles that of a tape-recorder machine, or a parrot. However, it is absolutely true to mention that the speaker of this sort of memorization is able to stop at any moment and begins to reason, comment on, or give the gist of what she/he is reciting before resuming her/his activity.

On the other hand, when an individual understands a written or spoken excerpt and then intentionally memorizes it, there is a greater possibility that he/she will forget the memorized text, simply because the emphasis is placed on memorization rather than comprehension. In this situation the learner exerts her/his greatest power to keep the verbatim-memorized pieces of language in mind via continual repetition. However, it is not unusual to find cases where individuals memorize items without understanding their meanings, for example, when memorizing telephone numbers, or when children sing a song they do not comprehend. This type of memorization can be referred to the so-called rote learning. Hornby (2010, p. 1333) defines rote learning as the process of learning something by repeating it until you remember it rather than by understanding the meaning of it. Not only this type of memorization is time-consuming, but it is extremely hard to perform. According to Vadidya (1996) rote learning is not meaningful in the process of internalization. It is arbitrary and verbatim in nature. It stays close to the cognitive structure of the learner but does not get integrated there.

\section{Previous Studies}

Most of the research gives accounts on the types of memorization, evaluates its use as a learning strategy, and investigates the interrelation between comprehension and this strategy. Yusuf's study (2010, p. 40) results showed that memorization had a positive effect on the research participants' academic achievements. Furthermore, it was considered as an effective tool for brain empowerment, illustration enhancement, and oration feature. The researcher underlined the importance of comprehending what is to be memorized. Oanh \& Hien (2006) studied memorization as a learning strategy. They aimed to identify learners' as well as teachers' beliefs about learning English in relation to memorization, and the MS effect on the process of learning. It was found that both teachers as well as learners made distinction between good and bad memorization. They suggested that memorization could satisfy certain needs of language learners; in addition, learners were advised to avoid rote learning. Mondrian (2002) investigated whether a word-learning method in which learners infer the meaning of unknown words from context and then memorize the meaning leads to better retention than one in which the meaning of unknown words are given in the form of translation followed by memorizing. The results revealed that the use of the meaning-inferred method leads to a similar level of retention as the meaning-given method. It was found that the first method was time-consuming and inefficient. The purpose of Porter's (2014) study was to 
find out if students would benefit more in retention and knowledge acquisition from the memorization method than the conceptual understanding method. The results showed that although the students who were taught using the memorization method were not able to score as high on the posttest as the other group, the trend indicates that they continued to increase in knowledge and retention.

Ozkan \& Kesen (2008) investigated EFL students' beliefs about memorization in language learning. It was found that memorization was among the most frequently used strategies. The subjects preferred memorization especially vocabulary memorization. It was also found that the educational system urged them to memorize. They recruited this strategy in writing more than in speaking. Li \& Chun's (2012) study showed that students used the memorization strategy almost as frequently as the elaboration strategies. The results showed that the MS has more strength in predicting students' reading performance than the elaboration strategy.

Many researchers (e.g., Matron et al., 1993) investigated the association between memorization and comprehension. Their studies showed that high achieving students made a less extreme distinction between understanding and memorizing. In contrast they made a clear distinction between rote memorization which they rejected and understanding that they supported. Ehrilich (1982) conducted a study in which the subjects were tested for comprehension and recall immediately after reading the text and a week later. The results showed that the recall performances increased as a function of the "degree" of comprehension of the text. Sachs \& Chan's (2003) study results showed that understanding the learning material was much more important than being able to reproduce it. Safdar's (2013) work compared the achievement of the secondary school science students taught through meaningful learning approach and the rote learning approach. The analysis of data revealed evidence for a major role of relevant cognitive structure in meaningful learning. Altaj (2014) conducted a study to identify and investigate the drawbacks of using the MS. The results showed that the majority of the learners were in favor of understanding a material rather than memorizing it.

To some up, the studies showed that: (1). The MS is one of the most frequently used learning strategies. (2). In certain situations memorization has a positive effect on the learning process. (3). Rote learning has to be avoided; instead, learners have to comprehend the meaning of what they hear or read.

\section{Statement of the Problem}

It has been noticed that EFL learners at all language-learning stages in Iraq and the region often complain that acquiring English is an extremely complicated process. In most countries, including Iraq, learners are not provided with enough opportunities to use English as a means of communication either in the classroom or outside the classroom. Furthermore, the common method of teaching English, in schools and, sometimes, even in some universities, depends on translating the study materials into the learners' mother language. Teaching is based on copying teacher's notes from the board, or/and information contained in prescribed textbooks. These important pieces of information are memorized in order to be copied down in tests and examinations. These examinations are, thus, memory-based rather than application, process-based or skills-based. This situation has made learners resort to memorization as a technique for learning English because it is rewarding and easy to carry out.

This study was conducted to measure the frequency of use of the MS by EFL learners, elicit information regarding their evaluation of its use, and find out the reasons that drive them to use memorization as a learning technique. It also sheds light on the problems learners encounter when memorizing study materials. The results of the research are expected to enlighten and convince educationalists that there are other alternatives and avenues, in addition to memorization, that could be adopted to improve the process of learning English.

\section{Research Questions}

The main purpose of this study is to answer the following questions:

(1). Which areas of language are most frequently memorized?

(2). What are the students' reasons for using memorization?

(3). What are the drawbacks of using the MS?

\section{Method}

\subsection{Participants}

The population sampled in this study was sixty-six full-time Arabic- speaking Iraqi students enrolled in the department of English, College of Arts, AL-Iraqia University. They were randomly selected from among students in the second, third and fourth grades. Thus, the sample included students of various competencies. The researcher thought this procedure would make it possible to elicit various, sound, and reliable responses. Their 
ages ranged from 19 to 25. They had studied English among other subjects taught in Arabic, for eight years before joining the college. The majority of the students were not proficient in English. Their ability to read and write in English was better than other language skills.

\subsection{Instrument}

The data was collected through a questionnaire written in English (See Appendix A). It aimed to give answers to the study questions by eliciting the participants' beliefs about the MS application in language learning. When developing the questionnaire, the researcher made use of his long experience in teaching English, the discussions he held with experts, and the available literature in this area. The draft copy consisted of 19 questions. It was submitted to three professionals in the field of English to decide its face validity. They unanimously agreed that the questionnaire was suitable and the vocabulary of the items were readily understood. In the light of their observations, some items were modified; in addition, one question was dropped because it did not serve the purposes of the study. Fifteen students from the same department participated in the pilot study. They were asked to note down and explain any difficulty they faced in understanding the test items. It was found that all the items were suitable except 3 which failed to meet test-designing demands because they were either too difficult to understand or repeated the same ideas.

The final version of the questionnaire constituted 15 items. Items 5, 6, 10 and 11 included multiple responses, which in turn were considered independent items, and the participants were instructed that it was possible for them to choose more than one response for each item. For example, question 5 embraces 5 answers. Since a respondent might use the MS to learn more than one subject matter, he/she could choose more than one answer. Accordingly, the number of the items contained was 30. For this reason, the percentage of each response was calculated individually. It was thought that this procedure would serve the purposes of the study in that it provided more flexibility and opportunities for learners to give accurate responses. The answers to the questionnaire were governed by the type of questions, thus, the multiple-choice answers took a variety of forms. Accordingly, there were scaled, yes/no, and true/false answers.

The questionnaire included four parts. The first part was designed to elicit general information. The second part was an attempt to identify the various subject matters (grammatical rules, vocabulary meanings, literary texts, pronunciation and definitions) that the respondents used to memorize. It measures the respondents' frequency of use of the MS for each subject matter. The third part identifies the reasons behind the subjects' tendency to use the MS. The fourth part probed the problems encountered by learners who adopted this strategy.

\subsection{Procedure}

The questionnaire was administered to all the participants in their regular English classes during the second semester of the academic year, 2016. In order to foster the reliability and credibility of the learners' responses, in addition to enriching the study with extra information, the participants were provided with sheets of paper to report as much as they could on any topic in the questionnaire. The researcher asked them to give more justifications for selecting a certain response. They were given clear and fully- explained directions and were told that it was possible for them to choose more than one option when giving their responses for items 5,6 , and, 10, and 11 (See Appendix A). The respondents were allowed to use Arabic to augment and clarify their evaluation responses.

\section{Data Analysis and Discussion}

After administering the questionnaire to all the subjects of the sample, the researcher collected the answer sheets. Each subject delivered two sheets: the questionnaire answer sheet and the participant- comment sheet. Each participant's response was allotted one score, then the total number of responses for each item was assigned a percentage, then statistically analyzed and individually discussed. The maximum score for each item was 66, while the minimum was 1 .

Table 1 below provides information about the respondents' use of the MS. It was found (item 1) that they evaluated their ability in English as being good or acceptable (45.4\%). They also revealed that they enrolled in the English department because learning English was their own choice (Item 2.a. 81\%). 
Table 1. Number and percentage of each item responses

\begin{tabular}{|c|c|c|}
\hline Item no. & No. of responses & Percentage \\
\hline 1.a. & 6 & 9 \\
\hline 1.b. & 30 & 45.4 \\
\hline 1.c. & 30 & 45.4 \\
\hline 1.d. & 0 & 0 \\
\hline 2.a. & 54 & 81 \\
\hline 2.b. & 12 & 18 \\
\hline 3. a. & 30 & 45.4 \\
\hline 3.b. & 0 & 0 \\
\hline 3.c. & 24 & 36 \\
\hline 3. d. & 12 & 18 \\
\hline 3.e. & 0 & 0 \\
\hline 4.a. & 61 & 92 \\
\hline 4.b. & 5 & 7 \\
\hline $5 . \mathrm{a}$ & 56 & 84 \\
\hline $5 \mathrm{~b}$. & 10 & 15 \\
\hline $5 \mathrm{c}$. & 4 & 6 \\
\hline $5 \mathrm{~d}$. & 31 & 46.9 \\
\hline 5.e & 63 & 95.4 \\
\hline 6.a & 55 & 83 \\
\hline 6.b. & 10 & 15 \\
\hline $6 . c$ & 6 & 9 \\
\hline 6.d. & 30 & 45.4 \\
\hline $6 . \mathrm{e}$ & 2 & 3 \\
\hline 6.f. & 57 & 86 \\
\hline 7.a. & 39 & 59.9 \\
\hline 7. b. & 27 & 40.9 \\
\hline $8 . \mathrm{a}$ & 51 & 77 \\
\hline 8.b. & 0 & 0 \\
\hline 8.c. & 12 & 18 \\
\hline 8.d. & 3 & 4.5 \\
\hline $8 . \mathrm{e}$ & 0 & 0 \\
\hline 9.a. & 0 & 0 \\
\hline 9.b. & 39 & 59 \\
\hline 9.c. & 27 & 41 \\
\hline 9.d. & 0 & 0 \\
\hline 9.e. & 0 & 0 \\
\hline 10.a & 48 & 72.7 \\
\hline $10 . \mathrm{b}$ & 40 & 60.6 \\
\hline 10.c & 50 & 75 \\
\hline 10.d & 6 & 9 \\
\hline 11.a & 15 & 22 \\
\hline 11.b. & 25 & 37.8 \\
\hline 11.c & 60 & 90 \\
\hline 11.d & 10 & 15 \\
\hline 12.a. & 15 & 22.7 \\
\hline 12. b. & 51 & 77 \\
\hline 13.a. & 12 & 18 \\
\hline 13.b. & 54 & 81.8 \\
\hline 14.a. & 0 & 0 \\
\hline 14.b. & 66 & 100 \\
\hline 15.a. & 57 & 86 \\
\hline 15.b. & 9 & 13.6 \\
\hline
\end{tabular}

It was also found that $45 \%$ of the respondents always used memorization as a learning strategy (Item 3.a), while \%36 (item 3.c) of them used it occasionally when they found it necessary. Moreover, their use of the MS $(92 \%)$ dated back to their primary schooling (Item 4). This result seemed reasonable for specialists in education in Iraq indirectly adopt an approach that encourages the use of memorization as a learning strategy. Children at the primary school stage are usually required to memorize letters, songs, sentences, etc. Educationalists believe 
that high-level skills such as inferring implied meaning have to be excluded, simply because at this stage priority has to be given to establishing language basics. Only after these basic language rules are internalized, we can move to teaching more complex skills. These basic skills include mastering grammatical, syntactic, and spelling rules, correct pronunciation, and reading comprehension. When language rules are memorized, they would be retained lifelong. They believe in the proverb which says, "Learning in the early childhood is like engraving a figure in stone".

The audio-lingual approach adopted in Iraq in the seventies of the last century might also be responsible for the popular use of the MS in Iraq. One of the main principles of this theory is that repetition of language patterns leads to habit formation. In the future, learners would be able to use the memorized elements of language automatically and then begin to release themselves from the controlled use of language to freer applications in real-life situations. For this reason memorization as a learning strategy, is highly recommended for EFL learners in general and beginners in particular. The learners who did not use this strategy pointed out that they focused only on the main points of the material they learned.

\subsection{Frequency Use of the Memorization Strategy}

Item 5 gives an answer to the first study question, "Which aspects of language are most frequently memorized?" Items $5 \mathrm{a}$ (vocabulary meaning) and 5.e (definitions) and 5d. (literary texts) got the highest percentage (84\%, $95.4 \%$, and $46.9 \%$ ) respectively). Learners resort to this strategy to increase their amount of memorized words. This would help them a lot handle various language activities. They used to look up new words, translate them into Arabic and then memorize their meanings. Despite the fact that learning new words is useful, the memorized words are subject to be forgotten. Gu \& Johnson's (1996) study revealed that the participants believed that memorization was an unreliable strategy. They thought that vocabulary should be carefully studied and should be used in context. The results of the present study showed that students were very careful to learn definitions and literally texts by heart because these matters were written in a very superb, unique and individual style (e.g., poetry) compared to other styles used in other language areas (e.g., conversation). Moreover, the respondents admitted that they resorted to this technique to recommend gaining better marks. The result of the study (Item 5.c) made it clear that the participants $(6 \%)$ did not support the view that grammatical rules should be memorized because, as they asserted, "Rules are to be understood and practised". Besides, it was found that few respondents $(15 \%)$ memorized words pronunciation (Item $5 . b$ ), while the majority considered their teacher as the best model to be idolized and imitated.

\subsection{Reasons for Using the Memorization Strategy}

Item 6 presents the reasons that motivated the learners to recruit the MS in their learning process. Among the six reasons suggested, the respondents placed heavy emphasis on the first and last reasons. Item 6.a shows that $83 \%$ of the questioned learners strove to improve their achievements through memorizing study materials. The use of the MS seemed to be the shortest and simplest way to realize their goals. They believed that their memorization-dependent answers would yield good marks. This conclusion could be reasonable if we take into consideration the contrasting relation between $6 \mathrm{a}$. and $6 \mathrm{f}$. In $6 \mathrm{f}$. the majority $(86 \%)$ of the respondents were reluctant to exercise other strategies that demand complex mental processes such as getting the main points or interpreting implied meanings. Such sophisticated strategies demand the utilization of various contextual clues to infer and understand the intended meaning. It seemed that effective and ineffective participants prefer applying the MS simply because they were not introduced to challenging activities like the ones mentioned above.

Lack of confidence in ability to learn English is a devastating factor in the process of learning; therefore, EFL learners try to snatch any available tool that might help them make progress. Thus, $45.4 \%$ (Item $6 . \mathrm{d}$ ) of the respondents supported the view that the MS gained them more confidence when they spoke, wrote or sat an exam in English. Very few learners (Item 6c: 9\%) believed that their teachers urged them to memorize and, on the other hand, it was found that only (3\%) of the respondents used the MS when they found a material difficult to understand (Item 6.e). This result gave evidence that the respondents as well as their teachers were not in favour of rote learning. The subjects declared they could not learn anything unless it was entirely understood. They added that it was possible to recite or re-write an understood and memorized material automatically without paying too much attention to the content of the produced language. When asked whether using the MS improved their gains in the examinations, $59.9 \%$ of the respondents gave positive answers (Item 7 a.) while (40.9\%) gave negative ones (Item 7.b).

\subsection{Drawbacks of Using the Memorization Strategy}

Despite the positive effects of the memorization process, some problems might negatively affect its advantages. Item 8.a. which elicits information about comprehending memorized materials got the highest percentage (77\%). 
This result indicated that the participants believed that understanding a material should precede its memorization. The score gained by item 6 .e above, where only 2 participants $(3 \%)$ memorized materials that they did not comprehend, gave a clear-cut evidence that the score of $8 \mathrm{a}$. is reasonable and reliable.

Forgetting memorized materials is one of the main chronic problems inflicted on EFL learners. Weinstein (1998) states that "high school and college students are well versed at retaining content knowledge long enough to take exams, but dreadfully, inept at maintaining that knowledge in long term memory". Item $9 \mathrm{~b}$ showed that $59 \%$ of the sample often forgot the memorized material and $41 \%$ sometimes could not remember it (Item 9c). This state refers to the short amount of time spent on memorizing subject matters; furthermore, some participants disclosed that their mere target was to pass the exam rather than learning English. In this case, the memorized information might not move to the long-term memory and eventually was subject to forgetfulness.

In order to solve the forgetfulness problem, the respondents used various techniques. They reported that they applied these techniques alternatively, i.e., if one technique proved unproductive, they moved to the next one. The presented results (Item 10.a.) showed that $72.7 \%$ of the learners tried to remember the forgotten segment. However, (\% 60.6) of them reported that once they forgot a key word, they often got stuck and forgot the entire text (Item 10b). In this situation, they usually tried to reproduce or recite the whole material from the beginning, hoping that a key word might be recovered and they would be put on the right track again. Interestingly, $75 \%$ (Item 10 c.) of the questioned learners noted that in case the first two techniques did not work, they usually presented the information contained in the material using their own words and styles. They mentioned that, though this technique was difficult, risky, and time consuming, they found it interesting and challenging. Actually, some of them pointed out that they did not adopt the MS; however, their memorization of language resulted from continuous revision of the material. It can be deduced that these learners understood the material before memorizing it, and that memorization took place when they tried to reinforce their command over the learned material. Very few learners (9\%) complained that sometimes when they began to produce language, oral speech in particular, most of the language elements faded away, leaving them in a state of embarrassment (Item 10.d). Even some learners who fully wrote memorized materials complained that they often got low marks in their examinations, simply because they gave answers that contained unnecessary information. They disclosed they could not differentiate between important and unimportant memorized information. As a result, they wrote everything they remembered, hoping the teacher might choose the points she/he considered as answers for their questions.

Item 11 tackles the techniques used to retrieve the forgotten meanings of words. Most of the learners $(90 \%)$ preferred checking a dictionary to find the meanings of words (Item 11c), rather than asking for help (Item 11d: $15 \%)$. This technique helped them avoid embarrassment and enjoy autonomous learning. Twenty-five (37.8\%) respondents tried to remember words by constructing their individual physical images found in real life situations (Item 11b). The present researcher thinks that this notion is completely sound since every word in a language makes a scene, no matter whether it represents a concrete or abstract entity. Human beings are able to remember and use words because of the bridge that connects abstract sounds or letters to real objects found on the ground. For example, the word cheerful is usually related to certain features and behaviors that characterize a person who enjoys this psychological state. Creating this state of relation was problematic for some of the learners. Item 11a. shows that few respondents $(22 \%)$ were inclined to remember the shape or pronunciation of the words to be remembered, because, as they noted, this process is exhausting.

Item 12 enquires whether the users of the MS were capable of going beyond it a step further, and exercise strategies that demand a higher level of thinking such as comprehending implied meaning, writing notes, or summarizing contents of various subject matters. Results showed that $15(22.7 \%)$ of the questioned sample were able to make inferences or give summaries for two reasons: first, they practised these skills during the course of their studies and, second, they had full control over the learned materials. $77 \%$ of the them mentioned that such strategies were not easy to apply because they used to have materials and activities void of exercising such high-level thinking strategies.' Another problem that the respondents( \%81.8) underwent was that when they gave a memorized oral speech, they used to look worried and speak hurriedly for fear of losing a key word which might lead to losing the stream of words (Item 13.b). They admitted that there was no room for thinking in that situation because their purpose was to deliver their speech to the audience perfectly as much as possible. Therefore, they looked passive, had no eye contact with the audience they addressed, and mostly got confused. For this reason, their teachers were not in favour of using this strategy because they were not able to interact with the audience due to lack of naturalness in communication. Here, the learner acts like a programmed machine; consequently, the audience might get bored, lose interest and attention. In addition, there was a unanimous agreement (Item 14.b: 100\%) that the use of the MS needs a lot of time and effort to perform because it requires 
the literal retrieval of the oral as well as the graphic shape of the memorized material. The learner is not free to select and learn the material he thinks it is necessary, rather she/he has to memorize the whole bulky material. When asked whether they preferred examination questions whose wordings matched the material that they had memorized, the majority gave positive responses (Item. 15. b. 86\%). Though most of the respondents pointed out that this type of questions was unfruitful, making them stagnant, they liked it because it would be easier for them to locate the answer (e.g., in reading comprehension examinations), and the possibility of getting higher marks was highly recommended.

\section{Conclusion}

This study was implemented to assess the utility of using the MS strategy that could facilitate the process of learning English. It was found that though the participants commonly used the MS at all learning stages in Iraq, their use was confined to specific areas of language, namely, vocabulary, terms definitions, and literary extracts. The MS was used to improve their achievements in English and get more confidence when presenting oral language or producing written materials. Despite the fact that memorization can help learners internalize language rules, priority was given to understanding. The main problems encountered by the participants included forgetting what had been memorized, having no inclination to handle tasks that demand higher cognitive processes (e.g., relating ideas to make inferences, spotting the main points, making conclusions). In addition to being time-consuming and difficult to perform, there is a big chance that the MS turns its followers into slaves. And the price for breaking the fetters of memorization to the free world of thinking is costly, but not impossible.

\section{Implications}

In the light of the study findings, it is suggested that learners of English, especially, at the early stages of language learning, have to be convinced that the use of the intentional MS is extremely advantageous as it familiarizes them with the various English language systems: the phonetic, grammatical, lexical, and more importantly, the socio-linguistic system. These rules can be unconsciously internalized by memorizing literary extracts, reading comprehension passages, songs, words used in exemplary sentences etc. The learners, through this process, are turned into acquirers who depend on their conscious and unconscious linguistic competencies when producing and receiving spoken or written materials. If these two channels of language learning (conscious and unconscious learning) are merged into a single learning programme, an amazing progress could be achieved. When a learner is asked to give the spelling of the word bicycle, for example, she/he would immediately give the correct answer. Actually, we owe this result to the implicit and explicit memorization. Meanwhile, it would be preferable to explain to the learners the occasions when memorization becomes a useful or harmful strategy. Learners have to be cautioned against using rote memorization. In addition, it is inadvisable to depend solely on a single strategy to learn English. The fact that has to be underlined here is that memorization is a strategy among other various strategies that can be jointly recruited to enhance and empower the process of learning English. These learners are to be sensitized to the contextual clues that should be exploited to interpret their spoken or written language. They have to be given the chance to analyse, reason and explore by themselves what is behind the opaque walls of an utterance.

\section{References}

Al Taj, M. M. Y. (2014). Reducing Memorization by EFL Undergraduates, Haijah University-Yemen. $\begin{array}{llll}\text { International journal of Scientific Research, } & 3(1), & 105-107 .\end{array}$ http://dx.doi.org/10.15373/22778179/JAN2014/36

Chamot. A., O’Malley, J., Kuper, L., \& Impink-Herandez, M. (1987). A Study of Learning Strategies in Foreign Language Instruction. Va. Interstate Research Associate.

Cohen, A. (1998). Strategies in learning and using a second language. New York: Addison Wesley Longman.

Cook, V. (1994). Linguistics and Second Language Acquisition. London: Macmillan.

Cotterall, S., \& Reinders, H. (2004). Learner Strategies: A guide for teachers. RELIC Portfolio Series.

Ehrilich, M. (1982). An Experimental Study of the Relation between comprehension and Memorization of a Text. Advances in Psychology, 9, 157-168. http://dx.doi.org/10.1016/S0166-4115(09)60049-2

Gu, Y., \& Johnson, R. (1996). Vocabulary Learning Strategies and Language Learning Outcomes. Language Learning, 46(4), 643- 679. http://dx.doi.org/10.1111/j.1467-1770.1996.tb01355.x

Hornby, A. S. (2010). Oxford Advanced Learner's Dictionary. Oxford: Oxford University Press.

Krashen, S., \& Terrell. T. (1983).The natural Approach Acquisition in the Classroom. Oxford: Pregmon. 
Li, J., \& Chun, C. K. (2012). Effects of Learning Strategies on Student Reading Literacy Performance. The Reading Matrix, 12(1), 30-38. Retrieved from http://www.readingmatrix.com/journal.html

Marton, F., Dall Alba, G., \& Beaty, E. (1993) Conceptions of learning. International Journal of Educational Research, 19(3), 277-300.

Marton, W. (1988). Methods in English Language Teaching: Frameworks and Options. London: Prentice Hall International.

McDonough, S. (1995). Strategy and Skill in Learning a Foreign Language. London: Edward Arnold.

Mondrian, J. (2002). The Effects of Inferring, Verifying, and Memorizing on the Retention of L2 Word Meanings. Studies in Second Language Acquisition, 25(4), 473-499. Retrieved from https://www.rug.nl/staff/j.a.mondria/ssla_2003.pdf

Nunan, D. (1989). Designing tasks for the communicative Classroom. Cambridge: Cambridge University Press.

O’Malley, J., Chamot, A., Stewner-Manzanares, G., Küpper, L., \& Russo, R. (1985). Learning strategies used by beginning and intermediate ESL students. Language Learning, 35(1), 21-46. http://dx.doi.org/10.1111/j.1467-1770.1985.tb01013.x

O’Malluey, J., \& Chamot, A. (1990). Learning Strategies in Second Language Acquisition. Cambridge: Cambridge University Press. http://dx.doi.org/10.1017/CBO9781139524490

Oanh, D., \& Hein, N. (2006). Memorization and EFL Students' Strategies at University Level in Vietnam. TESL-EJ, 10(2), 1-21. Retrieved from www.tesl-ej.org/ej38/a4.pdf

Ozkan, Y., \& Kesen, A. (2008). Memorization in EFL Learning. Academia, 35(3), 58-71. Retrieved from www.tesl-ej.org/ej38/a4.pdf

Porter, J. (2014). An Investigation in the Use of Memorizing as a Learning Method When Teaching Measurement in a Technology Education Classroom. Unpublished thesis. Utah State University. Retrieved from digitalcommons.usu.edu/cgi/viewcontent.cgi

Richards, J., \& Schmidt, R. (2013). Longman Dictionary of Language Teaching and Applied. Rout ledge: Great Britain. Linguistics. Essex: Longman.

Riley, P. (1981). Viewing Comprehension "L oeil ecoute". British Council. E. L. T. Document. The Teaching of Listening Comprehension. London.

Safadar, M. (2013). Meaningful learning and Rote Learning in Physics: a comparative study. Middle Eastern \& African Journal of Educational Research, 6, 60-77. Retrieved from www.majersite.org/issue6/5safdar.pdf

Vadidya, N. (1996). Science Teaching for the 21st Century (1st ed.). New Delhi: Deep and Deep Publications.

Wang, D. (1986). Optimal Language Learning Based on comprehension. British Council. E. L. T. Document. 124. Communicative Teaching. Oxford: paragons press.

Weinstein, C., Ridely, D., Dahi, T., \&Weber, E. S. (1998). Helping Students Develop Strategies for Effective Learning. Association for Supervision and Curriculum Development.

Yusuf, M. (2010). Memorization as a Learning Style: A Balance Approach to Academic Excellence. OIDA. International Journal of Sustainable Development, 1(6), 40-58.

\section{Appendix A}

\section{Questionnaire}

Dear student,

The main purpose of this questionnaire is to shed light on one of the commonest strategies used by learners; it also aims at verifying whether this strategy has a positive or negative effect on the process of learning English. We are interested in your own point of view. You can use a separate sheet of paper to write as much as you like to explain your point of view concerning each item. Thank you for helping us. 


\section{Part 1: General Data}

1. How would you evaluate your proficiency in English?

\begin{tabular}{l|l|l|l|}
\multicolumn{1}{c|}{ a. very good } & \multicolumn{1}{c}{ b. good } & \multicolumn{1}{c|}{ c. acceptable } & \multicolumn{1}{c|}{ d. bad } \\
\hline a. no. $=6$ & b. no. $=30$ & c. no. $=30$ & d. no. $=0$ \\
P. $=9 \%$ & P. $=45.4 \%$ & P. $=45.4 \%$ & P. $=0 \%$ \\
\hline
\end{tabular}

2. Was English your first choice?
a. Yes
b. No

no. $=54$ $\mathrm{P} .=81 \%$ no. $=12$ $\mathrm{P} .=18 \%$

3. Do you use memorization as a strategy for learning English?

\begin{tabular}{|l|l|l|l|l|}
\multicolumn{1}{c}{ a. always } & \multicolumn{1}{c}{ b. often } & \multicolumn{1}{c}{ c. sometimes } & \multicolumn{1}{c}{ d. rarely } & \multicolumn{1}{c}{ e. never } \\
\hline no. $=30$ & no. $=0$ & no. $=24$, & no. $=12$ & no. $=0$ \\
P. $=45.4 \%$ & P. $=0 \%$ & P. $=36 \%$ & P. $=18 \%$ & P. $=0 \%$ \\
\hline
\end{tabular}

4. How long have you been using this method?

a. since my primary schooling b. since my secondary schooling.

\begin{tabular}{|c|c|c|c|}
\hline $\mathrm{no}=61$ & $\mathrm{P} .=92 \%$ & no. $=5$ & $\mathrm{P} .=7 \%$ \\
\hline
\end{tabular}

\section{Part 2: Frequency of Using the Memorization Strategy}

5. Which subject(s) demands the most use of this strategy?

$\begin{array}{ll}\text { a. Vocabulary meanings } & \text { b. pronunciation of words }\end{array}$

$\begin{array}{lll}\text { c. grammatical structures } \quad \text { d. literary extracts } \quad \text { e. definitions } & \end{array}$

\begin{tabular}{|ll|ll|ll|ll|ll|}
\hline a. & no. $=56$ & b. & no. $=10$ & c. & no. $=4$ & d. & no. $=31$ & e. & no. $=63$ \\
P. & P. $=84 \%$ & P. & P. $=15 \%$ & P. & P. $=6 \%$ & P. & P. $=46.9 \%$ & P. & P. $=95.4 \%$ \\
\hline
\end{tabular}

\section{Part 3: Reasons for Using the Memorization Strategy}

6. Why do you use the memorization strategy?

a. I want to get better marks.

b. It helps me learn English quickly. It improves my language skills: speaking, reading, writing, vocabulary learning and pronunciation.

c. My teachers prefer answers that depend on this strategy.

d. I become more confident when I participate in classroom activities, write in English, and sit an exam.

e. I often memorize the study materials that I do not understand.

f. I often memorize the study materials because the use of other strategies such as inferencing or getting the main points is difficult, jeopardizing my goal of getting good marks.

g. other reasons.

\begin{tabular}{|c|c|c|c|c|c|}
\hline $\begin{array}{cc}\text { a. } & \text { no. }=55 \\
& \mathrm{P} .=83 \%\end{array}$ & $\begin{array}{cc}\text { b. } & \text { no. }=10 \\
& \text { P. }=15 \%\end{array}$ & $\begin{array}{cc}\text { c. } & \text { no. }=6 \\
& \text { P. }=9 \%\end{array}$ & $\begin{array}{ll}\text { d. } & \text { no. }=30 \\
& \text { P. }=45.4 \%\end{array}$ & $\begin{array}{ll}\text { e. } & \text { no. }=2 \\
& \text { P. }=3 \%\end{array}$ & $\begin{aligned} \text { f. } \quad \text { no. } & =57 \\
\text { P. } & =86 \%\end{aligned}$ \\
\hline
\end{tabular}

7. Do you get higher marks when using the memorization strategy?

\begin{tabular}{|c|c|c|c|}
\hline Yes & & & \\
\hline a. $n o=39$ & $\mathrm{P} .=59.9 \%$ & b. no. $=27$ & $\mathrm{P} .=40.9 \%$ \\
\hline
\end{tabular}




\section{Part 4: Drawbacks of Using the Memorization Strategy}

8. I understand what I memorize.

\begin{tabular}{|l|l|l|l|l|}
\multicolumn{1}{c}{ a. always } & \multicolumn{1}{c}{ b. often } & \multicolumn{1}{c}{ c. sometimes } & \multicolumn{1}{c}{ d. rarely } & \multicolumn{1}{c}{ e. never } \\
\hline a. no. $=51$ & b. no. $=0$ & c. no. $=12$ & d. no $=3$ & e. no. $=0$ \\
P. $=77 \%$ & P. $=0 \%$ & P. $=18 \%$ & P. $=4.5 \%$ & P. $=0 \%$ \\
\hline
\end{tabular}

9. I forget what I memorize.

\begin{tabular}{|l|l|l|l|l|}
\multicolumn{1}{c}{ a. always } & \multicolumn{1}{c}{ b. often } & \multicolumn{1}{c}{ c. sometime } & \multicolumn{1}{c}{ d. rarely } & \multicolumn{1}{c}{ e. Never } \\
\hline $\begin{array}{l}\text { a. no. }=0 \\
\text { P. }=0 \%\end{array}$ & b. no. $=39$ & c. no. $=27$ & d. no. $=0$ & e. no. $=0$ \\
& p. $=59 \%$ & P. $=41 \%$ & P. $=0 \%$ & P. $=0 \%$ \\
\hline
\end{tabular}

10. How would you behave in case of forgetting part of a text you have memorized?
a. I try to remember it.
b. I try to recite the whole stuff again.

c. I write the material using my own words.

d. I get confused, embarrassed and frustrated, and mostly give up the task.

\begin{tabular}{|l|l|l|l|}
\hline a. no. $=48$ & b. no $=40$ & c. no. $=50$ & d. no. $=6$ \\
P. $=72.7 \%$ & P. $=60.6 \%$ & P. $=75 \%$ & P. $=9 \%$ \\
\hline
\end{tabular}

11. What will you do if you forget the meaning of a word?

a. I try to remember its shape and its pronunciation.

b. I try to visualize its meaning by relating it to an object or an image that represents it in real life.

c. I check a dictionary.

d. I ask someone for help

\begin{tabular}{|l|l|l|l|}
\hline a. no $=15$ & b. no. $=25$ & c. no. $=60$ & d. no. $=10$ \\
P. $=22 \%$ & P. $=37.8 \%$ & P. $=90 \%$ & P. $=15 \%$ \\
\hline
\end{tabular}

12. It is difficult for me to make inferences, comments, or summarize what I memorized.

a. false

b. true

\begin{tabular}{|ll|ll|}
\hline a. no. $=15$ & P. $=22.7 \%$ & b. no. $=51$ & P. $=77 \%$ \\
\hline
\end{tabular}

13. When orally presenting a memorized material, I cannot think about what I am speaking, moreover, my eyes get passive.

a. False
\begin{tabular}{|ll|ll|}
\hline b. no. $=12$ & P. $=18 \%$ & b. no. $=54$ & P. $=81.8 \%$ \\
\hline
\end{tabular}

14. The use of the memorization strategy demands a long time and a great effort.
a. false
b. true

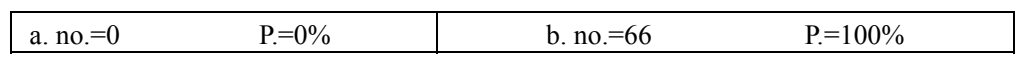

15. I prefer questions whose wordings matches that in the memorized text.
a. false
b. true

\begin{tabular}{|ll|ll|}
\hline a. no. $=9$ & $\mathrm{P} .=13.6 \%$ & b. no. $=57$ & $\mathrm{P} .=86 . \%$ \\
\hline
\end{tabular}




\section{Copyrights}

Copyright for this article is retained by the author(s), with first publication rights granted to the journal.

This is an open-access article distributed under the terms and conditions of the Creative Commons Attribution license (http://creativecommons.org/licenses/by/3.0/). 